\title{
Política cultural, mecenato e a mercantilização da cultura: o Brasil no roteiro internacional das exposições de arte
}

\section{Marina Araujo Miorim}

1 Mestre em Educação pela Faculdade de Educação da Universidade Estadual de Campinas (UNICAMP) e Bacharel em Sociologia pela UNESP-Araraquara. Professora de Sociologia na Educação Básica. E-mail: marinaamiorim@gmail.com

RESUMO: O presente artigo pretende provocar uma reflexão introdutória acerca das relações entre as políticas culturais contemporâneas e as exposições temporárias de arte que têm aportado no Brasil, desde meados da década de 1990. Através dos interesses econômicos que estão conectados a esse processo, diante da particularidade do capitalismo financeiro, busca-se apresentar um panorama das relações entre as exposições de arte e a economia globalizada, bem como problematizar a ação do Estado brasileiro nessa dinâmica. No momento, a intenção é mapear os movimentos em torno de algumas exposições, para então apreendermos sua eficácia, seja para a formação de público - sensibilização, fruição, humanização - seja para a acumulação de capital.

Palavras-chave: Política Cultural. Mecenato. Exposições de Arte. Capitalismo Financeiro.

Cultural policy, mecenate and mercantilization of culture: Brazil in the international script of art exhibitions

ABSTRACT: This article intend to provokes an introductory reflection about the relations between the current cultural policy and the temporary art exhibition, that has arrived in Brazil since the mid-1990s. Bypassing the economic aspects connected to this process, given the particularity financial capitalism, the article tries to present an overview of the globalized economy in dialogue with the art exhibition, as well to problematizes the action of the Brazilian State in this dynamic. At the time, the intention is to map the movements around some exhibitions, so that we can grasp their effectiveness, whether for the formation of public - awareness, fruition, humanization - or for the accumulation of capital.

Keywords: Cultural Policy. Patronage. Art Exhibition. Financial Capitalism.

O Brasil, assim como grande parte dos países ocidentais, viu, ao longo do século $X X$, o campo da cultura se fortalecer enquanto demanda democrática e buscou incrementar, do ponto de vista governamental, as possibilidades de produção e consumo aos bens culturais. $O$ que tentamos compreender, nesse caso, é o perfil dessas ações políticas, bem como suas relações com outros espaços da vida social pois, como destaca o pesquisador José Carlos Durand, a "pluralidade de interesses ativos na área cultural" é enorme (DURAND, 2001, p.66). Isto posto, é preciso se despir de uma leitura ingênua de que a cultura, e especialmente as artes - no âmbito da produção e da fruição - seria um espaço de criatividade e liberdade desconectado em relação as outras esferas da vida.

Diante dessa perspectiva, o presente artigo pretende provocar algumas reflexões introdutórias acerca das relações entre as políticas culturais contemporâneas e a oferta crescente de exposições de arte tempo- 
rárias que aportam no Brasil. Tal estudo implica em delinear, com mais precisão, as relações entre o poder público e os patrocinadores privados desses eventos artísticos para termos um panorama mais complexo das ações e interesses que podem estar conectados a elas, de modo que possamos problematizar os discursos de democratização da cultura, vigentes na contemporaneidade.

Qual o papel das artes visuais na sociedade contemporânea? Como as determinações econômicas se relacionam com a produção e a fruição artística? Como as políticas culturais são fomentadoras da experiência estética e quais setores da sociedade as impulsionam?

Essas são algumas das perguntas que mobilizam as reflexões iniciais acerca das exposições internacionais de arte que têm aportado no Brasil a partir da década de 1990 e que dinamizaram, assim como complexificaram, o circuito cultural brasileiro num espectro que vai do patrocínio artístico contemporâneo a um expressivo fenômeno de público, passando pelas ações governamentais e as intersecções com a economia globalizada.

\section{ARTES VISUAIS E ECONOMIA GLOBALI- ZADA}

Se é verdade que a produção e a circulação de objetos de arte sempre contou com o apoio de mecenas (FEIJÓ, 1983; SUANO, 1986; AMARAL, 2001), o que se vê no Brasil e no mundo, especialmente a partir da década de 1980, é um protagonismo sem precedentes da lógica mercantil nas artes, e uma evidente aceleração no tempo de criação e fruição que pode colocar em xeque o entendimento de que a arte serve ao enri- quecimento da sensibilidade humana.

Diante dessa perspectiva que destaca a força do capital no espaço do fazer artístico, o pesquisador Luiz Marques aponta como algo bastante problemático a emergência da pop art nesse processo, nos anos de 1960. Para o autor, a partir desse movimento/escola "tudo se converte em performance" (MARQUES, 2001, p.59). E uma performance que passa a vicejar ganhos econômicos cada vez maiores, especialmente, para quem está envolvido com a organização de eventos ligados a essa escola e, posteriormente, a toda produção artística.

Em relação a isso talvez possamos avançar para um questionamento, qual seja, de como a economia capitalista globalizada, ao gerar uma aceleração da produção e, consequentemente, do consumo, tornou também a arte uma mercadoria, transformada em grandes espetáculos episódicos da vida. Assim, a pop art, ao estabelecer um diálogo com o público através de símbolos extraídos do imaginário que cerca a cultura de massa, teria sido mais facilmente cooptada pela lógica do capital e inserida na vida cotidiana. Na esteira desse fenômeno, outras escolas e movimentos artísticos teriam sido dragados para alimentar a dinâmica do capitalismo financeiro.

É importante esclarecer, contudo, que os objetos artísticos, em outros contextos históricos, já carregavam a condição de mercadorias. Inclusive sendo produzidas sob encomenda pelos grandes mecenas. Contudo, a particularidade contemporânea consiste em inserir a arte dentro de uma cadeia econômica-produtiva. Ou seja, o valor estético perde, cada vez mais, espaço para os valores econômicos. Nesse movimento, a pesquisadora Tatiana Sampaio Ferraz aponta que se formam "redes complexas de circu- 
lação de capital econômico em torno da produção artística" (FERRAZ, 2015, p.117). E os objetos artísticos, por carregarem uma especificidade em relação às outras mercadorias possuem, como destaca David Harvey, algo que é encantador ao capitalismo: a possibilidade de um rendimento monopólico, através do qual gera-se um fluxo ampliado de renda devido a um controle exclusivo que se tem de uma mercadoria que possui qualidades especiais.

Destarte, quando nos referimos à globalização, tomamos a compreensão de David Harvey que a define, não como uma unidade indiferenciada, "mas como composição geograficamente articulada de atividades e relações capitalistas globais" (HARVEY, D., 2005 , p. 155). Portanto, nesse processo que compreende um desenvolvimento geográfico irregular a partir das necessidades do capital haverá, segundo o autor, a construção de uma governança urbana que dialoga com interesses especulativos e que não negligenciará, como possibilidade de rendimento, nenhuma esfera da vida social. Assim, o capital se internacionalizou, apoiado em uma diminuição dos custos em transporte e comunicação e "o espaço de competição mudou de forma e escala no decorrer do tempo" (HARVEY, D. 2005, p.148). Essa nova dinâmica econômica reverberou também no campo das artes, tanto na produção como nas formas de distribuição e consumo. Os interesses do mercado, e o seu modo de atuação nesse setor, tornam-se, por isso, fenômenos a serem estudados e compreendidos em sua complexidade, diante da particularidade histórica do capitalismo financeiro.

Dessa maneira, pode-se estabelecer um paralelo da organização performática da arte contemporânea, a qual se referia Luiz
Marques, com um modelo de difusão e curadoria emergente nos espaços de exposição das artes visuais que foi destaque no artigo do jornalista Phillippe P. Célérier.

No texto para o Le Monde Diplomatique, de fevereiro de 2007, o autor apresentou um quadro bastante instigante quanto ao perfil das exposições em importantes museus ao redor do mundo a partir dos anos 2000. Segundo Célérier, os museus teriam se convertido em espaços de geração de renda e não de fruição artística. Por essa razão eles estariam mais preocupados em criar dinâmicas de visitação rápida, com exposições temporárias de forte apelo publicitário em torno de obras consagradas que passaram a viajar para várias partes do mundo.

Esses intercâmbios artísticos envolvem, sem dúvida, um conjunto de agentes e interesses bastante volumosos. São produtores, curadores, patrocinadores privados, instituições públicas, companhias de seguro e de transporte para o deslocamento de obras de alto valor artístico e comercial.

De acordo com a análise do jornalista, os museus cedentes das obras puderam ver seus recursos aumentarem com esses "empréstimos", bem como os que recebem as exposições garantiram um incremento dos seus cofres pela ampliação da visitação. $O$ mercado brasileiro de arte não ficou fora desse movimento, e o objetivo deste artigo é discutir algumas de suas particularidades.

\section{AS EXPOSIÇÕES TEMPORÁRIAS DE ARTE NO BRASIL}

No caso brasileiro, observa-se a frequência de um número cada vez mais expressivo de pessoas nas exposições temporárias de arte, o que sugere, inicialmente, um inte- 
resse maior pela arte consagrada, não obstante, quando investigamos o teor dessa experiência cultural a partir das relações estabelecidas em outras esferas sociais econômicas e políticas - que envolvem esses eventos e intercâmbios artísticos, outros aspectos menos aparentes desse fenômeno começam a se revelar e exigir mediações cada vez mais complexas. De início é preciso se perguntar como, e por que, o país alcançou uma posição de destaque no ranking internacional de público, como destaca o The Art Newspaper - imprensa especializada no cenário das artes ao redor do mundo. Divulgada no site do governo federal, o país aparece na lista com três exposições entre as 20 mais visitadas do mundo em 2015. São elas: Picasso e a Modernidade Espanhola, em décimo lugar, com 620.719 visitantes, no Centro Cultural Banco do Brasil - Rio de Janeiro; na décima segunda posição, também no CCBB-RJ, Kandinsky: tudo começa num ponto; e o décimo quinto lugar foi para Salvador Dalí, com 530 mil visitantes, no Instituto Tomie Ohtake, em São Paulo1.

A partir de um breve levantamento de informações a respeito das exposições destacadas acima, pudemos identificar uma lista de patrocinadores, copatrocinadores e apoiadores para a concretização desses eventos no Brasil, que ocorrem através de uma política cultural normatizada, majoritariamente, pela Lei Rouanet. A tabela abaixo indica esses agentes envolvidos nas exposições:

1 http://www.brasil.gov.br/cultura/2016/04/exposicoesbrasileiras-estao-em-ranking-das-mais-visitadas-em2015

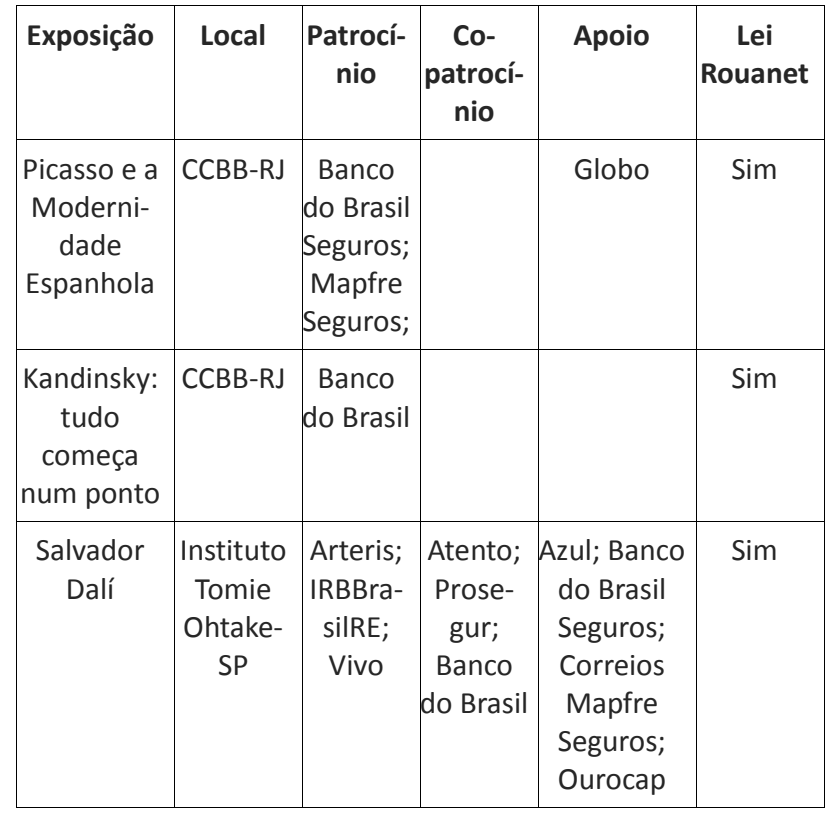

Exposições no Brasil que entraram para o ranking internacional de visitação (ano de 2015) e suas conexões com a iniciativa privada e com as políticas públicas

Diante do quadro, retomemos alguns questionamentos que orientam esta análise: quais são os interesses que motivam a iniciativa privada a realizar patrocínios para eventos culturais? Como se estabelecem os vínculos entre esses patrocinadores e as políticas culturais vigentes no Brasil?

Apenas para estabelecermos um parâmetro para a compreensão do conceito de Política Cultural, utilizaremos a noção de Maria das Graças Rua, que o compreende como uma ação organizada dos governos, no sentido de viabilizar recursos, ou bens públicos, para atender demandas da sociedade no âmbito da produção e do consumo da cultura.

A ascensão das políticas públicas, de maneira geral, está associada à experiência democrática dos Estados liberais de suprir de forma sistematizada as necessidades percebidas ou reivindicadas pela população. Especificamente no campo da cultura esse movimento dos governos se organiza com mais clareza e força na segunda metade do 
século XX, em consonância com o avanço do neoliberalismo e a financeirização.

No caso brasileiro, será durante a primeira era Vargas que o governo se propõe, de maneira mais sistemática, a organizar o campo cultural atendendo, de certo modo, aos apelos dos modernistas que clamavam por isso desde a década de 1920. Com isso o Estado viabilizou um leque maior de possibilidades do fazer e do fruir artístico mas, o campo das artes visuais, em particular, teria ficado muito mais a cargo da iniciativa privada do que propriamente do Estado (CALABRE, 2007; SANTOS, 2004). Essa situação pode ser observada a partir da fundação do MASP (1947), do MAM-RJ (1948) e da BIENAL (1951), todos criados a partir de projetos e recursos do empresariado brasileiro e, em alguns casos com o apoio de agentes internacionais, como é o caso das doações de Nelson Rockefeller para o MAMSP (AMARAL, 2001; CABRAL, 2016).

Com o nascimento do Ministério da Educação e da Cultura, em 1953, e reconhecendo a importância e a visibilidade do MASP, do MAM-RJ e da BIENAL, o governo federal passou a destinar recursos para essas instituições, apesar delas se organizarem prioritariamente por meio da iniciativa privada (CALABRE, 2007).

O protagonismo do empresariado não seria, portanto, algo novo para o universo das artes visuais no Brasil. Tampouco a relação de fomento público para as iniciativas culturais propostas por essa elite. $\mathrm{O}$ que se tem nesse processo, a partir da década de 1990, é a complexificação dessa relação, especialmente quando se investiga as leis que passam a normatizar esse fenômeno.

Em dezembro de 1991 é promulgada a lei 8.313 - Lei Rouanet - que garante a renúncia fiscal de empresas que assumem o patrocí- nio de eventos culturais. Com isso começa a se delinear de forma mais clara o caminho para as políticas culturais no Brasil como um campo de intersecção entre os interesses do mercado e a agenda política.

Durante o governo de FHC, a Lei Rouanet sofrerá algumas transformações e se transformará em "um importante instrumento de marketing cultural das empresas patrocinadoras. [...] subvertendo [assim] o projeto inicial de conseguir a parceria da iniciativa privada em investimentos na área da cultura" (CALABRE, 2007, p.8). Contudo, para além do marketing gerado pelo patrocínio a esses eventos pode-se aferir outros interesses motivadores para esse mecenato contemporâneo. Frequentemente, especialmente para grandes eventos de arte (o que é o caso das exposições de arte internacionais a que estamos nos referindo), tem-se situações em que $100 \%$ do capital investido pode ser abatido do imposto de renda dos patrocinadores. Ou seja, "o capital investido pela empresa, que gera um retorno de marketing, é todo constituído por dinheiro público, aquele que seria pago de impostos. 0 resultado final é o da aplicação de recursos que eram públicos a partir de uma lógica do investidor do setor privado." (CALABRE, 2007, p.8).

Assim como Calabre, outros analistas vêm problematizando essa dinâmica que, segundo eles, garantiu que o mercado passasse a ditar o caminho das políticas culturais no país a partir dos seus interesses (CALABRE, 2007; DURAND, 2001; SANTOS, 2004; AMARAL, 2001). E o resultado desse processo se daria pela concentração na aplicação de recursos. Uma concentração geográfica e personalística, na medida em que artistas já consagrados recebem grandes investimentos, pois são esses que vão 
trazer retorno de marketing para as marcas que os apoiam.

É importante que ressaltemos que esse movimento das políticas culturais centradas nos departamentos de marketing das grandes empresas converge com o fortalecimento de uma agenda neoliberal em todo o mundo. Mas diante da lista de patrocinadores, copatrocinadores e apoiadores que temos para as exposições mais recentes, e que tem sido um grande sucesso de público, fica mais uma pergunta: Seria apenas o marketing cultural o resultado desejado por essas empresas? Quando olhamos para as empresas envolvidas com as exposições de grande destaque no ano de 2015, podemos notar que algumas são desconhecidas do grande público. E isso se dá por uma questão lógica: sua área de atuação não se relaciona com pessoas físicas, com os visitantes desses eventos artísticos.

A pesquisadora Valéria Pilão, nos dá pistas preciosas para desmistificar esse interesse centrado nos departamentos de marketing das empresas patrocinadoras. Segundo a autora, o marketing é apenas a aparência do fenômeno. Uma aparência que se apoia em um forte discurso ideológico das empresas e do Estado, mas que não dá conta de demonstrar "as diferentes maneiras de inserção da cultura no processo de acumulação" (PILÃO, 2017, p.27).

Deste modo, retomemos a questão central que fomenta esta reflexão: quais os interesses que motivam esses patrocínios? Essa problematização só poderá ser respondida com uma investigação que aprofunde os meandros que este artigo levanta2. No momento, a intenção é mapear os

2 Este artigo sintetiza algumas das problematizações sobre políticas culturais e mercantilização da arte no movimentos em torno de algumas exposições, para então apreendermos sua eficácia, seja para a formação de público - sensibilização, fruição, humanização - seja para a acumulação de capital.

\section{ECONOMIA E MECENATO CULTURAL}

A ascensão da sociedade burguesa, no século XVIII produziu o fenômeno do mecenato artístico (da produção à circulação) tal como o conhecemos atualmente ${ }^{3}$. No campo das artes visuais os Estados liberais compreenderam a força das exposições de arte para a formação de um novo homem que emergia daquele processo histórico, e a necessidade de delinear uma nova subjetividade ancorada nos interesses do capital. Nesse sentido, a educação para uma moral burguesa tornou as coleções de arte acessíveis ao público e criou mecanismos de visitação para um novo espaço de socialização que fora criado, os museus.

Nos Estados Unidos que, desde 1773 possuem coleções de arte abertas ao público, não só o conjunto das peças expostas reflete os ideais da democracia liberal, mas também o investimento para construção, manutenção e aquisição de acervos, bem como decisões de funcionamento e curadoria ocorrem através de parcerias entre o governo e as "sociedades de amigos do museu", patrocinadores privados.

Brasil, tema de projeto de pesquisa em nível de doutorado.

3 No caso brasileiro, a expressão mecenato é utilizada pelo poder público em seus textos oficiais como sinônimo do termo Incentivo Fiscal, também chamado de renúncia fiscal. Segundo o site do Ministério da Cultura, essa seria "uma forma de estimular o apoio da iniciativa privada ao setor cultural" (http://www.cultu ra.gov.br/programa-nacional-de-apoio-a-culturapronac-). 
A maneira como se pulverizou a experiência liberal fez emergir novos atores no cenário cultural e essa multiplicação de funções e posições chegou ao século XX de maneira muito complexa. Quando nos deparamos com o conjunto de pessoas que se articulam para organizar as exposições internacionais de arte temos indícios concretos a respeito desse movimento extensivo das ações culturais.

A ação de Nelson Rockefeller junto da política de Washington4 e suas amizades, com Ciccillo Matarazzo e Yolanda Penteado, no Brasil da década de 1950 traz uma pequena evidência da complexidade de interesses no campo da cultura para a consecução de objetivos econômicos e ideológicos.

Atualmente, quando olhamos para as empresas patrocinadoras das exposições de arte que chegam ao país nos deparamos, majoritariamente, com instituições brasileiras e estrangeiras de capital aberto. Isso nos mostra que a internacionalização do capital também tornou mais fluido o investimento em cultura, e os objetivos associados a essas ações mais cheios de nuances.

\section{O QUE SOBRA PARA O PÚBLICO?}

Como exposto anteriormente, as exposições de arte temporária que têm aportado no Brasil a partir da década de 1990 possuem condições que as colocam como um fenômeno a ser investigado e compreendido, sobretudo pela complexidade das redes que

4 A esse respeito consultar o artigo de Fátima A. Cabral "Guerra Fria Cultural - particularidades sobre a arte $e$ política no Brasil e Argentina". Revista Novos Rumos, do Programa de Pós-Graduação em Ciências Sociais da UNESP/Marília e do IAP - Instituto Astrojildo Pereira/SP, no número 53, volume 2 , do segundo semestre de 2016, p.134-168, ISSN 0102-5864. as costuram. E, nesse contexto, temos a questão do público como uma das variáveis a ser problematizada.

Assim, apenas para termos uma ideia inicial: a frequência na Pinacoteca de São Paulo entre os anos de 1995 e 1997, não alcançou 190 mil visitantes, embora a exposição da obra de Rodin, nesse museu, tenha sido considerada, à época, um grande sucesso de público. Já em 2015, com a exibição da obra do australiano Ron Muek, a mesma instituição recebeu mais de 400 mil visitantes $^{5}$, em, aproximadamente, 4 meses.

Já as exposições de Picasso e a Modernidade Espanhola, Kandinky: tudo começa num ponto e Salvador Dalí, foram destacadas dentro do rol das 20 exposições mais visitadas no mundo no ano de 2015. Para incrementar essa lista podemos, ainda apresentar outros fenômenos de público recentes, tais como, Os impressionistas, CCBBSP: aproximadamente, 600 mil visitantes, 2012; e Frida Kahlo, Tomie Ohtake: 600 mil visitantes, 2016.

Esses dados colocam o Brasil no topo de duas listas, ainda mais específicas, o Top-10 das exposições de arte Pós-Impressionista e Moderna, e o Top-10 de arte Contemporânea ${ }^{6}$. Uma das hipóteses para compreender esse fenômeno de público talvez seja o fato de não termos, no acervo do país, tantas obras que contemplem algumas escolas e artistas consagrados. Se relacionarmos isso com a análise de Luiz Marques e Aracy A-

5 Dados disponíveis em https://www.apsisconsultoria. com.br/blog/noticias/o-ano-das-exposicoes-blockbuste rs-no-brasil/ e http://g1.globo.com/sao-paulo/noticia/ 2015/02/exposicao-de-ron-mueck-faz-pinacoteca-bater -recorde-de-publico.html

6 Top-10 de arte Pós-Impressionista, Moderna e Contemporânea http://www.brasil.gov.br/cultura/2016 /04/exposicoes-brasileiras-estao-em-ranking-das-maisvisitadas-em-2015 
maral, de que a Bienal fracassou em compor um acervo de obras internacionais para o espaço museológico brasileiro, essa hipótese ganharia força, e seria um subterfúgio poderoso para legitimar ideologicamente os financiamentos privados a esses eventos.

Não obstante, esse fenômeno das grandes exposições internacionais, incluindo a Bienal como a precursora desse movimento, traz inquietações acerca da força do mercado nas possibilidades de fruição artística. Nessa problemática poderíamos destacar: a manipulação do gosto na direção de um consumismo irracional e volátil das experiências estéticas; a valoração das obras de arte e a aquisição de acervos a partir de uma pretensão de investimento e especulação financeira; a ampliação do mercado do setor de turismo através de um status cultural; e a ampliação de um mercado de trabaIho próprio vinculado a esses grandes espetáculos das artes visuais contemporâneas (AMARAL, 2001).

Uma das diferenças que Aracy Amaral estabelece entre a Bienal e as exposições temporárias contemporâneas, contudo, diz respeito ao fato da regularidade. A certeza de que a Bienal aconteceria a cada dois anos geraria, segundo a autora, um movimento imprescindível para garantir a formação de público, de quadros artísticos e de políticas públicas, o que qualificaria o pensar e o fazer da arte fortalecendo um movimento mais democratizante (AMARAL, 2001).

Entretanto, quando as políticas públicas passam a fortalecer $o$ agente financeiro investidor enquanto um novo sujeito do sistema das artes, colocando a seu critério as iniciativas para os eventos culturais, tem-se o deslocamento das intenções dessa agenda de democratização para o de acumulação, segundo os interesses de uma cadeia econômica que ainda não fora, completamente, explorada.

\section{CONSIDERAÇÕES FINAIS}

Esse artigo, como expresso anteriormente, buscou apresentar uma reflexão introdutória acerca das relações entre as políticas culturais contemporâneas, a economia globalizada e as exposições de arte temporárias apresentadas para o público brasileiro, desde meados da década de 1990. Nesse sentido, há um longo caminho a percorrer para consolidar informações que possibilitem uma clareza dos mecanismos utilizados pelo campo econômico para dominar, a partir de suas conveniências, os espaços de fruição artística. Contudo, essa é uma investigação necessária se quisermos garantir que as políticas públicas para o campo da cultura sejam, efetivamente, democráticas.

Em trabalho anterior abordei essa perspectiva democratizante esperada das políticas públicas (MIORIM, 2014) que vem de encontro com a Constituição de 1988, essa que consolidou a cultura como um elemento da "cesta básica" de direitos dos brasileiros. A legitimidade das políticas culturais, portanto, vem ancorada na nossa carta magna que, reconhecendo o valor da experiência estética para o enriquecimento, e ampliação das possibilidades de emancipação dos sujeitos atribui à União, Estados e Municípios a responsabilidade de proporcionar meios de acesso à cultura, respeitando a diversidade na produção, promoção e circulação de bens culturais.

A despeito desse marco constitucional democratizante em relação a esfera cultural, o que se vê e tem sido, amplamente problematizado por diversos autores, é a apro- 
priação que o capital tem feito da arte no sentido de suas conveniências, amparado por leis de incentivo fiscal que subvertem o ideal democrático. Esse tipo de apropriação que se dá em relações, por vezes, nebulosas carecem de maiores investigações para, no futuro, termos subsídios suficientes para romper "a corrente de mercantilização a que os bens artísticos estão submetidos" (MIORIM, M. 2014, p.135), a fim de enriquecermos o cotidiano humano sem o arbítrio dos interesses mercantis.

\section{BIBLIOGRAFIA}

AMARAL, A. Bienais ou Da impossibilidade de reter o tempo. REVISTA USP, São Paulo, n.52, dezembro/fevereiro 2001-2002, p.1625.

CABRAL, F. A Guerra Fria Cultural - particularidades sobre a arte e política no Brasil e Argentina. Revista Novos Rumos, do Programa de Pós-Graduação em Ciências Sociais da UNESP/Marília e do IAP - Instituto Astrojildo Pereira/SP, no número 53, volume 2 , do segundo semestre de 2016, p.134168, ISSN 0102-5864.

CALABRE, L. Políticas culturais no Brasil: balanços e perspectivas. Trabalho apresentado no III ENECULT - Encontro de Estudos Multidisciplinares em Cultura, realizado entre os dias 23 a 25 de maio de 2007, na Faculdade de Comunicação/UFBA, Salvador Bahia - Brasil. Disponível em: http://www. cult.ufba.br/enecul2005/LiaCalabre.pdf.

Acesso em 25 mai 2017.

CÉLÉRIER, P. P. Quando os museus viram mercadoria. Le Monde Diplomatique Brasil, Fevereiro, 2007. Disponível em: http://diplo matique.org.br/quando-os-museus-virammercadoria/. Acesso em 25 mar 2017.

DURAND, J.C. Cultura como objeto de Políti- ca Pública. São Paulo Perspec., São Paulo , v. 15, n. 2, p. 66-72, Apr. 2001. Disponível em: http://www.scielo.br/scielo.php?script =sci_arttext\&pid=S0102-883920010002000 10. Acesso em10 mar. 2017.

FEIJÓ, M. C. O que é política cultural. Coleção Primeiros Passos. Ed. Brasiliense: São Paulo, 1983.

FERRAZ, T. S. QUANTO VALE A ARTE CONTEMPORÂNEA? Novos estudos. CEBRAP [online]. 2015, n.101 [cited 2017-05-15], pp. 117-132. Disponível em: http://www.scielo. $\mathrm{br} / \mathrm{scielo}$.php?script=sci_arttext\&pid=S0101 -33002015000100117 . Acesso em 28 set. 2017.

HARVEY, D. A arte de lucrar: globalização, monopólio e exploração da cultura. In. Por uma outra comunicação. MORAES, D. (organizador). Editora Record. Rio de Janeiro São Paulo, 2005, p.139-171.

MARQUES, L. A Bienal e o novo sistema das artes. REVISTA USP, São Paulo, n.52, dezembro/fevereiro 2001-2002, p.56-63.

MIORIM, M.A. Teatro e educação dos sentidos: a experiência da Brava Companhia. Editora Appris, Curitiba, 2014.

MORAES, D de. A arte como mercadoria na obsessão do lucro. Blog da Boitempo, 2013. Disponível em: https://blogdaboitempo. com.br/2013/09/11/a-arte-como-mercador ia-na-obsessao-do-lucro/. Acesso em 15 mai. 2017.

PILÃO, V. As diferentes formas de inserção da cultura no processo de acumulação de capital: a particularidade brasileira. (Tese de doutorado) Universidade Estadual Júlio de Mesquita Filho. Faculdade de Filosofia e Ciências - Marília, Programa de Pós Graduação em Ciências Sociais. Marília, 2017. RUA, M.G Políticas Públicas, Departamento de Administração, UFSC - Florianópolis, 2012. Disponível em: http://www.academia. 
edu/11259556/Politicas_Publicas_Maria_da s_Gra\%C3\%A7as_Rua. Acesso em 23 mar. 2017.

SANTOS, Myrian Sepúlveda dos. Museus brasileiros e política cultural. Rev. bras. Ci. Soc., São Paulo , v. 19, n. 55, p. 53-72, June 2004 . Disponível em: http://www.scie lo.br/scielo.php?script=sci_arttext\&pid=S01 02-69092004000200004\&lng=en\&nrm=iso.

Acesso em 10 Mar. 2017.

SUANO, M. O que é museu. Coleção Primeiros Passos. Ed. Brasiliense: São Paulo, 1986.

Artigo recebido em 28 de setembro de 2017.

Aprovado em 29 de novembro de 2017. 